\title{
Erratum to: Hormone Receptor-Negative Breast Cancer: Undertreatment of Patients Over 80
}

Anna Weiss, MD ${ }^{1}$, Abraham Noorbakhsh, BA ${ }^{1}$, Christopher Tokin, MD $^{1}$, David Chang, PhD, MPH, MBA ${ }^{1}$, and Sarah L. Blair, MD $^{2}$

${ }^{1}$ University of California San Diego, San Diego, CA; ${ }^{2}$ Moores UCSD Cancer Center, San Diego, CA

ERRATUM TO: ANN SURG ONCOL (2013) 20:3274-3278

DOI 10.1245/S10434-013-3115-2

Abraham Noorbakhsh's family name is correct as presented in this erratum.

The online version of the original article can be found under doi:10. 1245/s10434-013-3115-2.

(C) Society of Surgical Oncology 2014

Published Online: 22 July 2014

A. Weiss, MD

e-mail: a3weiss@ucsd.edu 